\title{
The ecosystem functioning dimension in conservation: insights from remote sensing
}

\author{
Javier Cabello • Néstor Fernández • Domingo Alcaraz-Segura • \\ Cecilio Oyonarte $\cdot$ Gervasio Piñeiro $\cdot$ Alice Altesor $\cdot$ Miguel Delibes • \\ José M. Paruelo
}

Received: 25 October 2011/Accepted: 11 September 2012

(C) Springer Science+Business Media B.V. 2012

\begin{abstract}
An important goal of conservation biology is the maintenance of ecosystem processes. Incorporating quantitative measurements of ecosystem functions into conservation practice is important given that it provides not only proxies for biodiversity patterns, but also new tools and criteria for management. In the satellite era, the translation of spectral information into ecosystem functional variables expands and complements the more traditional use of satellite imagery in conservation biology. Remote sensing scientists
\end{abstract}

J. Cabello $(\varangle) \cdot$ N. Fernández $\cdot$ D. Alcaraz-Segura

Departamento Biología Vegetal y Ecología, Centro Andaluz para la Evaluación y Seguimiento del Cambio Global, Universidad de Almería, Ctra. Sacramento s/n La Cañada de San Urbano,

04120 Almería, Spain

e-mail: jcabello@ual.es

N. Fernández $\cdot$ M. Delibes

Department of Conservation Biology, Estación Biológica de Doñana, Spanish Council for Scientific Research-CSIC, Av. Américo Vespucio s/n, 41092 Sevilla, Spain

D. Alcaraz-Segura

Environmental Sciences Department, University of Virginia, 291 McCormick Road, Charlottesville, VA 22904, USA

D. Alcaraz-Segura

Departamento de Botánica. Facultad de Ciencias, Campus Universitario de Fuentenueva, Universidad de Granada, 18071 Granada, Spain

D. Alcaraz-Segura · G. Piñeiro · J. M. Paruelo

Laboratorio de Análisis Regional y Teledetección, IFEVA-Facultad de Agronomía, Universidad de Buenos Aires y CONICET, Av. San Martín, 4453, 1417 Buenos Aires, Argentina

C. Oyonarte

Departamento de Edafología y Química Agrícola, Centro Andaluz para la Evaluación y Seguimiento del Cambio Global, Universidad de Almería, Ctra. Sacramento s/n, La Cañada de San Urbano, 04120 Almería, Spain

A. Altesor · J. M. Paruelo

Departamento de Ecología, Facultad de Ciencias, Universidad de la República, Iguá 4225,

Montevideo, Uruguay 
have generated accurate techniques to quantify ecosystem processes and properties of key importance for conservation planning such as primary production, ecosystem carbon gains, surface temperature, albedo, evapotranspiration, and precipitation use efficiency; however, these techniques are still unfamiliar to conservation biologists. In this article, we identify specific fields where a remotely-sensed characterization of ecosystem functioning may aid conservation science and practice. Such fields include the management and monitoring of species and populations of conservation concern; the assessment of ecosystem representativeness and singularity; the use of protected areas as reference sites to assess global change effects; the implementation of monitoring and warning systems to guide adaptive management; the direct evaluation of supporting ecosystem services; and the planning and monitoring of ecological restorations. The approaches presented here illustrate feasible ways to incorporate the ecosystem functioning dimension into conservation through the use of satellite-derived information.

Keywords Conservation planning - Ecosystem functioning descriptors · Ecosystem monitoring · Environmental change · Protected areas · Restoration ecology $\cdot$ Species-environment relationships

\section{Introduction}

Conservation biology has been described as a mission-driven science (Soulé and Wilcox 1980), although its specific goals have changed over time (Meine et al. 2006). The preservation of biodiversity was the overall accepted objective for decades (Callicott et al. 1999). Recently, however, a more general concern for maintaining the capacity of ecosystems to sustain and regulate processes (e.g. nutrient and water dynamics, and carbon balance) has gained consensus (Goldman et al. 2008; Naidoo et al. 2008). In fact, a growing number of legislative agreements, such as the Convention on Biological Diversity, require specific management schemes that address the functioning of ecosystems (Frid et al. 2008) to explicitly consider the ecological processes that maintain biodiversity (e.g. Rouget et al. 2003) and the ecosystem services these processes provide (Armsworth et al. 2007).

The recent emergence of the biodiversity-ecosystem functioning paradigm (e.g. Naeem 2002; Hooper et al. 2005) has recognized the bidirectional relationship existing between the conservation of biodiversity and of ecosystem processes, and the need to incorporate ecosystem functioning parameters in conservation practice (Jax 2010). Why have few studies analyzed ecosystem functioning in the field of conservation biology? We have identified three possible (and not mutually exclusive) conceptual and logistic explanations for this deficiency. (1) In contrast to many variables operating at the individual or population levels, ecosystem functioning is characterized by "intangible" fluxes of matter and energy. Intangibility presents an added challenge in any discipline (Allen and Hoekstra 1992); however, it becomes particularly problematic in conservation biology given the strong link between this field and policy and decision-making. Actions involving easily recognizable and perceivable entities are more appealing to politicians, conservation managers, and the general public than "intangible" ones. Moreover, conservation biology has traditionally focused more on the evolution than on the thermodynamics of ecosystems (Callicott et al. 1999). (2) Despite the "inclusive" nature of conservation biology, conservationists typically do not receive the practical or theoretical training necessary to understand ecosystem processes, particularly those that are strongly related to the geophysical sciences. (3) Insufficient effort, especially for terrestrial ecosystems (in contrast 
see Frid et al. 2008 for marine ecosystems), has been devoted to identifying specific conservation tasks where techniques that study ecosystem functioning are particularly useful and enable a clear connection with managers and decision makers.

One feasible way to incorporate ecosystem functioning indicators into conservation is through the use of remote sensing tools (Duro et al. 2007; Gillespie et al. 2008; Horning et al. 2010). Traditionally, satellite imagery has been primarily used in conservation biology for classifying, describing, and mapping vegetation structure and species habitats (Kerr and Ostrovsky 2003; Pereira and David Cooper 2006), but not for ecosystem functioning characterization. Recently, this bias is being corrected with a slow but increasing number of articles appearing in main conservation journals that specifically incorporate satellite image products to address ecosystem functioning. A search in Scopus (May 10, 2012) in three leading journals in the field revealed that, among all of the conservation articles published since 2007 containing "remote sensing" in any of the search fields "title, abstract, or keywords" $(n=76)$, only a small proportion (from 10 to $30 \%$ ) specifically addressed ecosystem functioning issues: Biological Conservation-12 out of 41 , Biodiversity and Conservation-3 out of 25, and Conservation Biology-2 out of 10 .

Ecosystem functioning can be defined as the collective effect of multiple ecosystem processes that ultimately determines the rate of matter and energy fluxes (Hooper et al. 2005), such as primary production, ecosystem gas exchange, energy balance, evapotranspiration, nitrogen mineralization, decomposition, and nutrient loss. In this sense, the translation of satellite spectral information into functional attributes of ecosystems expands the value of remote sensing for conservation science. Spectral information has been successfully used to model functioning variables such as primary production (Ruimy et al. 1994), seasonality (Potter and Brooks 1998) and phenology (Reed et al. 1994) of carbon gains, evapotranspiration (Moran and Jackson 1991), surface energy balance (Hall et al. 1992), fraction of absorbed photosynthetically active radiation (fAPAR) (Gower et al. 1999), and precipitation use efficiency of ecosystems (Paruelo et al. 1999). These ecosystem attributes have a critical influence on population and community-level processes and may represent conservation targets per se. In this article, we review remote sensing approaches that favor the incorporation of ecosystem functioning variables into the theoretical development and practice of biological conservation. We also present examples of specific applications that use satellite-derived ecosystem functional variables to address conservation issues.

\section{Ecosystem functioning characterization through remote sensing}

The seasonal dynamics of carbon gains has been proposed as an integrative descriptor of ecosystem functioning given that it constitutes the input of energy into an ecosystem (Virginia et al. 2001) and, consequently, determines many other, strongly-related fluxes (e.g. secondary production, respiration, $\mathrm{N}$ uptake) (McNaughton et al. 1989). Carbon gain dynamics can be readily characterized from vegetation spectral indices strongly associated with the (spatio-temporal) patterns of primary production, such as the Normalized Difference Vegetation Index (NDVI) (Tucker 1979) or the Enhanced Vegetation Index (EVI) (Huete et al. 2002), both of which make use of the red and near infrared reflectances of the Earth's surface. Moreover, considering the direct relationship between vegetation indices and the fraction of photosynthetically active radiation (fAPAR) intercepted by green vegetation (Ruimy et al. 1994), it is possible to derive regional maps of Net Primary 
Production (NPP) utilizing radiation use efficiency values (Monteith 1977). As a result, NDVI or EVI seasonal measurements, at the ecosystem level and from regional to global scales, have emerged as the most suitable tools to quantify overall productivity and biomass (Running et al. 2004; Turner et al. 2006), the seasonality in productivity (Piñeiro et al. 2006; Potter and Brooks 1998) and the timing of other plant activities (i.e. phenological measurements) (Cleland et al. 2007). The combined analysis of these variables has been used to identify ecosystem functional types, providing an overall description of ecosystem diversity at the regional scale (Alcaraz-Segura et al. 2006; Paruelo et al. 2001).

In addition to vegetation indices, other variables derived from spectral data, such as albedo and surface temperature, have been recently incorporated into analyses to quantify ecosystem diversity and the conservation value of protected areas (Fernández et al. 2010). Albedo is a key component of ecosystem energy balance, with broad implications for the local climate and the internal dynamics of ecosystems (Bala et al. 2007). Furthermore, changes in albedo have been used to detect the ecological degradation of ecosystems, such as that due to overgrazing in deserts (Otterman et al. 2002) or changes in fire disturbance regimes in forests (Lyons et al. 2008). Surface albedo can be directly estimated from broad band reflectance data derived from satellite images (Liang 2000), which represent the amount of short-wave radiation that is reflected by the Earth's surface. Albedo is particularly important and useful in studying ecosystem functioning in biomes characterized by low vegetative cover (e.g. Fang et al. 2005) and where snow persists during part of the year (e.g. Callaghan et al. 2004), and its use has been increasing in forested regions (Ollinger et al. 2008). Surface temperature measures sensible heat and constitutes another key component of the ecosystem energy balance that has been used in conjunction with NDVI and albedo to identify ecosystem functional diversity (Fernández et al. 2010), as well as to monitor inter-annual vegetation dynamics (Julien and Sobrino 2009). In addition, different algorithms combine surface temperature, albedo, and NDVI to estimate heat partitioning into latent and sensible fluxes (Kustas and Anderson 2009). Understanding patterns of heat partitioning can help discern past species range shifts and anticipate future climate changeinduced alterations of biodiversity (Fischer et al. 2009).

\section{Incorporating ecosystem functioning into conservation biology practice}

Ecological processes described by remote sensing techniques, together with field studies or simulation models, can be used to obtain useful information and derive conservation actions for different biodiversity entities and organization levels (e.g. populations, species, or ecosystems) (Fig. 1). In this section, we outline specific targets based on examples drawn from the literature.

\section{Conservation of populations and species diversity}

The conservation of species populations and diversity has been the primary focus of conservation biology studies since the emergence of the discipline. Key research goals include understanding which habitat conditions (i.e. quantity and characteristics of the habitat) are required to ensure species persistence; understanding the effects of environmental variability on population parameters; and predicting how environmental change may affect the distribution, demography and viability of populations. All of these objectives involve diverse scales of biological organization requiring multidisciplinary approaches to their study, which has prompted a gradual incorporation of the principles and 


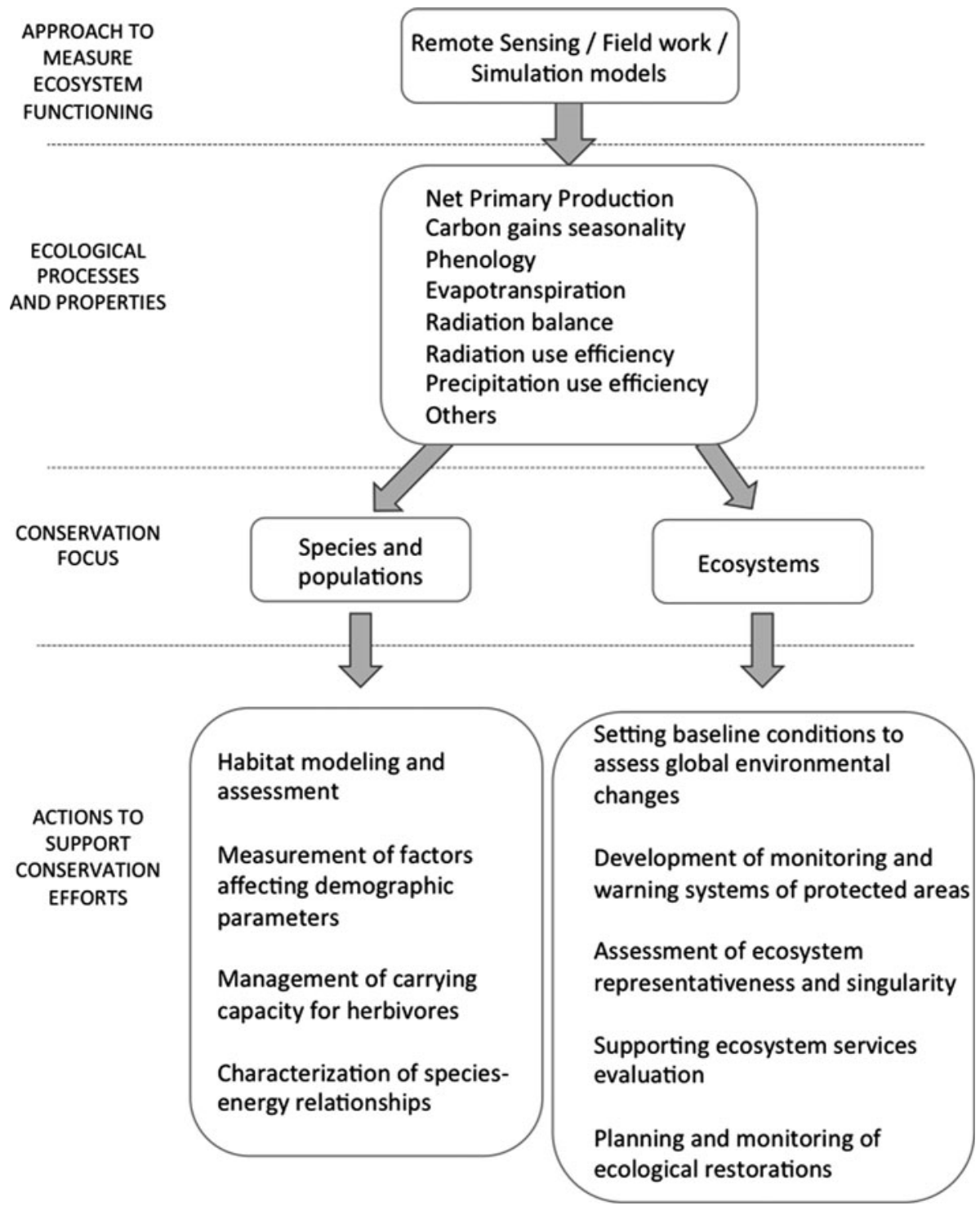

Fig. 1 General scheme of conservation applications derived from ecosystem functioning characterization using remote sensing approaches, among others. Ecological processes and properties may address different entities depending on the focus of the conservation requirements to derive specific actions

methods of many different research areas, ranging from genetics to landscape ecology. The inclusion of indicators of ecosystem functioning has the potential to contribute, in a similar way, to addressing these questions. Seminal reviews by Pettorelli et al. (2005), Gillespie et al. (2008), and Pettorelli et al. (2011) have highlighted the rapid increase in the use of spectral vegetation indices-mostly NDVI-in animal ecology research, as well as the great potential of this index for understanding the impacts of environmental change on species and populations. These approaches are essentially inspired by classical principles 
concerning the relationships between energy availability and the size and distribution of animal home ranges, vital rates of individuals, population size and density, and species richness. However, applications using ecosystem functioning indices in species conservation are still incipient. Here we discuss some representative examples illustrating the importance of increasing efforts in this direction.

\section{Habitat modelling and assessment}

Understanding the characteristics and the spatial distribution of species habitats is critical for assessing the conservation status of populations, designing reserves, predicting species distributions and their responses to environmental change, and preserving and restoring the ecological conditions required to sustain threatened populations. Species-environment models have become some of the most widespread tools used to address these questions (Guisan and Thuiller 2005), although they predominately rely on descriptors of spatial environmental heterogeneity, while neglecting the effects of temporal variability (but see e.g. Franklin 2010). Wiegand et al. (2008) showed that habitat assessment for an endangered population of brown bears (Ursus arctos arctos) in a marginal population in Spain was substantially improved by considering the effects of seasonal and inter-annual variability in ecosystem functioning. The species habitat quality was constrained by seasonal pulses in primary production as defined by NDVI: those areas where bears exhibited higher reproductive performance (i.e. high quality habitats) presented a stronger seasonality and a narrower spatial variability in ecosystem functioning. Furthermore, models showed that habitat quality can be ordered according to the dynamics of NDVI, consistent with the evolutionary adaptations of brown bears to track pulsed food resources. High-quality areas occurred under highly specialized and marginal ecosystem conditions which are important to preserve in order to maintain the population. This approach based on the identification of gradients of habitat quality, not just habitat suitability, helps to prioritize conservation targets, and the analysis of NDVI revealed the disproportionate impact that alterations in ecosystem functioning could have on species conservation.

In another example, habitat assessment for the Giant Panda (Ailuropoda melanoleuca) emphasized the importance of considering ecosystem phenology for its ability to capture information regarding both the distribution of food resources and human disturbances (Tuanmu et al. 2011). Models based on the Wide Dynamic Range Vegetation Index (WDRVI) facilitated the temporal transferability of model predictions and were appropriate for monitoring changes in wildlife habitat as reflected by changes in the phenology of the land surface.

These insights, combined with the availability of continuous, extensive remote sensing data, advocate the development of ecosystem monitoring protocols aimed at providing a continuous assessment of the status of the habitats of species. However, few attempts have been made in this area. Coops et al. (2009) proposed a Dynamic Habitat Index (DHI), which included the minimum, the mean and the variability of fPAR, and suggested that the regional analysis of DHI over time would help detect significant impacts on species and predict how distributions and diversity may be affected by environmental change. The successful incorporation of this or similar indices into conservation practice will require a rigorous evaluation of their capacity to quantify species habitat loss and degradation. In addition, practical issues such as the definition of species-specific thresholds of habitat change need to be resolved before these tools can be transferred to managers. 


\section{Population dynamics and viability}

Species conservation planning requires a thorough consideration of the factors affecting the size of populations and how this size varies in time and with environmental change (Boyce 1992). In essence, environmental factors affect population dynamics through their effects on reproduction, mortality and population growth and movement patterns, with all of these processes dependent on the ecosystem capacity to provide usable energy to organisms. Recent remote sensing applications have shown, for example, that fecundity in a population of Savanna elephants (Loxodonta Africana) was dependent on the seasonal levels of primary production in such a way that NDVI was a reliable predictor of yearly differences in population recruitment rates (Wittemyer et al. 2007). Furthermore, cycles in ecosystem productivity synchronized reproduction across the population and were responsible for population fluctuations, which have important implications for harvesting designs and species recovery efforts. NDVI also correlates with offspring survival in elephants (Wittemyer 2011) and other herbivores (Pettorelli et al. 2007), indicating that post-birth surrogates of primary production are also an important indicator of breeding success.

The correlation between indicators of primary production and survival rate has also revealed mechanisms of demographic synchronization among populations of migratory species. Schaub et al. (2005) demonstrated that the annual survival of storks (Ciconia ciconia) that nest in different parts of Europe was correlated with NDVI dynamics at a single wintering area in the Sahel, which appeared to affect the growth rate of breeding populations throughout Central Europe. In the endangered Egyptian vulture (Neophron percnopterus) a positive relationship has also been observed between NDVI measured within breeding territories and juvenile survival, and between NDVI and survival of all age classes in wintering areas (Grande et al. 2009).

Movements of individuals across the landscape have also been related to remotelysensed vegetation activity. Using evolutionary programming models in combination with spatio-temporal patterns of NDVI, Boone et al. (2006) predicted the migratory trajectories of wildebeest simulating the adjustment of evolutionary responses of animal movements to forage optimization. The relationship between herbivore movements and the spatial and temporal variability in primary production (Mueller et al. 2011) has important conservation implications, such as predicting the location of large herbivore herds (Musiega and Kazadi 2004) and assessing the negative impacts of land-use and linear infrastructures on population connectivity (Ito et al. 2005).

Ecosystem functioning can considerably help disentangle more complex questions such as the interaction between density-dependent and environment-driven demographic processes in determining population dynamics. Using the Enhanced Vegetation Index (EVI), Bardsen and Tveraa (2012) recently showed how increased vegetation greenness in summer compensated for negative density-dependence effects on individual reproduction costs, reproductive allocation and breeding success in female reindeers (Rangifer tarandus).

We expect that the opportunity to incorporate spectral indices of ecosystem functioning will represent an important advance in the modeling of population dynamics for species conservation. More traditional applications have demonstrated the importance of considering the variability in weather phenology for predicting population demography (e.g. Rodriguez and Bustamante 2003); however, the direct links between ecosystem phenology and population parameters were not easy to assess until the development of remote sensing applications. Vegetation indices have demonstrated their ability to outperform the predictive power of variables such as rainfall in population demography 
studies (Rasmussen et al. 2006), and they provide a more direct representation of the underlying ecological regulators. In addition, conservation prospects under a changing climate will require more careful consideration of the effects of environmental variability on population dynamics, taking into account changes not only in temperature and precipitation regimes (Verboom et al. 2010), but also in ecosystem-level processes.

\section{Managing carrying capacity for herbivores}

A major challenge for conservation practitioners is to devise management systems that integrate goals related to wildlife and local livestock activities (Madhusudan 2004). An objective and spatially-explicit quantification of aboveground net primary production (ANPP) and its intra- and inter-annual variability would allow for the delineation of sustainable stock densities and grazing areas and timing, based on the relationship between ANPP and herbivore consumption (Oesterheld et al. 1998; Oesterheld et al. 1992). A pilot system with domestic herbivores has already been implemented to support grazing management based on monitoring ANPP (estimated from data provided by the MODIS sensor) on extensive ranches in the Argentine Pampas (Grigera et al. 2007), and this system could be directly applied to protected areas (Oyonarte et al. 2010). Tracking both herbivore stock densities and ANPP can be used to monitor grazing impacts on grassland and savannas (Manseau et al. 1996) or to assess the role of overgrazing on desertification processes (Paruelo et al. 2008).

\section{Species-energy relationships and conservation}

Lastly, the conservation of biodiversity depends on our capacity to anticipate the effects of environmental variability on the species composition of communities. For this, the characterization of species-energy relationships on the basis of remote sensing has already contributed to the understanding of both geographic and fine-scale patterns in species diversity of birds, showing a direct relationship between seasonal species richness and seasonal measures of NDVI (Hurlbert and Haskell 2003). However, Phillips et al. (2010) noticed that sign and strength of the species-energy relationship in North America was context-dependent, suggesting that bird species richness was positively affected by primary production in low-energy areas but negatively affected in high-energy areas. They pointed out that these differences should be taken into account in the design of specific management strategies, including the manipulation of nutrients and vegetation and the management of disturbances such as fires, logging and grazing in order to favor bird communities. We must emphasize, however, that biodiversity management should focus on the maintenance and restoration of biodiversity, not maximizing species richness (Lindenmayer and Hunter 2010). Therefore, species-energy approaches will require a deeper understanding of the relationships between ecosystem energy and biodiversity values, such as the number of rare species and species evenness, in order to better contribute to conservation practices.

Despite the increasing popularity of vegetation indices such as NDVI and EVI in species ecology, the number of ecosystem functioning descriptors used in conservation applications is limited in comparison to the possibilities offered by remote sensing (e.g. see Pfeifer et al. 2012). A few studies have recently incorporated remote-sensing variables, such as fPAR (Coops et al. 2009), Net Primary Production (NPP) and Gross Primary Production (GPP) (Phillips et al. 2008; Phillips et al. 2010) in analyses of species richness. These indices purportedly provide a more straightforward description of the ecosystem variables of interest; however, there are a number of assumptions in their calculations as 
well as spatial and temporal accuracy differences that should be carefully considered. For example, the accuracy of GPP estimates varies highly depending on factors such as vegetation type, and these estimates may not improve the predictive value of EVI in some applications (Pfeifer et al. 2012). In addition to vegetation productivity, other ecosystem functioning indices have great potential to address species conservation problems, such as descriptors based on the energy balance of the land surface that provide information about land degradation (García et al. 2008) and disturbances (Mildrexler et al. 2009), which can be used to monitor impacts on species habitats.

Monitoring and selection of protected areas

\section{Protected areas as points of reference for monitoring global environmental changes}

Anthropogenic impacts can be monitored and assessed by comparing differences in ecosystem functioning of altered areas relative to areas less impacted by human activities (Schonewald-Cox 1988). This approach constitutes a long-standing argument for the conservation value of natural areas (Jenkins and Bedford 1973) and gives special importance to protected area networks, serving as reference systems across different environmental conditions. Several studies have used NDVI attributes (Alcaraz-Segura et al. 2008a, b, 2009b), surface temperature (Fernández et al. 2010), and actual evapotranspiration (Garbulsky and Paruelo 2004) to derive reference situations from protected area networks and to monitor global environmental changes, by comparing protected ecosystems with those subjected to greater human disturbance.

The availability of datarecords covering several decades (e.g. AVHRR/NOAA products) provides an opportunity to separate the effects on ecosystem functioning due to climatic or atmospheric changes from those related to land-use changes. For example, compared to protected areas, agriculture in temperate South America reduced $\mathrm{C}$ gains in highly productive systems and increased them in those systems with low productivity (Paruelo et al. 2001). These analyses also demonstrated that human modification resulted in more seasonal systems.

Other analyses have provided quantitative evidence for the ecological effectiveness of conservation policies at the national or global scale. Tang et al. (2011) provide a global analysis of the role of protected areas in maintaining ecological processes. They used NDVI dynamics as a measure of the variation over a 25 year period of plant production in the core, boundary and surroundings of more than 1000 protected areas. At a national level, Pelkey et al. (2000) assessed changes in vegetation condition with the aid of NDVI timeseries, observing that national parks and recreation areas in Tanzania presented significantly better conservation status than the non-protected areas. The NDVI seasonal dynamics were also used to detect differences in the phenological behavior of similar areas due to their different management regimes in natural parks of Spain (Alcaraz-Segura et al. 2008a; Durante et al. 2009).

\section{Development of monitoring and warning systems for protected areas}

Incorporating satellite-based indicators of ecosystem functioning may substantially improve monitoring and warning systems of protected areas (Duro et al. 2007). Ideally, ecological indicators must be able to capture the spatial and temporal variability of ecosystem processes over extensive areas and in different regions, and should be capable of tracking the integrity of ecological processes (Dale and Beyeler 2001). In addition, 
indicators should be sensitive to both long-term and rapid changes, particularly the latter when the aim is to devise alarm systems. Indicators of ecosystem functioning derived from spectral data match these criteria. For instance, a critical limitation to studying temporal dynamics of NPP and its relationship with climatic variables is the lack of long-term data (Jobbagy et al. 2002; Knapp and Smith 2001). Fortunately, this limitation may be mitigated by the availability of NDVI or EVI time-series. Paruelo et al. (2005), working in protected arid areas of southeastern Spain, found that attributes related to the spatial variability and temporal dynamics of absorbed photosynthetically active radiation (APAR) in areas with intense human modification (outside the protected area) displayed lower sensitivity to changes in precipitation than those areas under protection. The description of such differences in the response of APAR to water availability was proposed as the basis of a system for monitoring desertification of drylands.

On the other hand, since many satellites provide data with a 1-20 day frequency, monitoring satellite-derived functional indicators over time can be the basis of earlywarning systems that allow conservation managers to actively manage in the short term. This approach was used in the Assessment of African Protected Areas project (http://bioval.jrc.ec.europa.eu/APAAT/). Every 10 days, this alert system collects NDVI and other satellite-derived data as indicators of ecosystem health (Hartley et al. 2007). By comparing every new 10-day period with the same period in the historical record, significant anomalies are quickly identified and ranked to produce a shortlist of environmental events and protected areas that require further investigation and monitoring (Hartley et al. 2007). A similar idea has recently inspired a monitoring and warning system for the Spanish Network of National Parks based on the use of NDVI-derived functional indicators from MODIS images (http://www.magrama.gob.es/es/ministerio/organizacion/organis mos-publicos/organismo-autonomo-parques-nacionales-oapn/plan-seg-ev-pn/seguimientoecologico/). Furthermore, monitoring systems based on remote sensing can be extended to ecological forecast systems through the incorporation of ancillary data and simulation models. This is the case for the Terrestrial Observation and Prediction System of Yosemite National Park (Nemani et al. 2009) that incorporates operational satellite data, microclimate mapping, and ecosystem simulation models to characterize ecosystem status and trends from a functional perspective.

All these monitoring approaches to ecosystem functioning allow for cost-efficient monitoring schemes (Crabtree et al. 2009) and provide easy to interpret indicators of ecosystem response to environmental changes (Pettorelli et al. 2005). In addition, their implementation exhibits low impacts on ecosystems, a critical requirement for any monitoring system (Havstad and Herrick 2003).

\section{Assessment of ecosystem representativeness and selection of protected areas}

At the ecosystem level, functional attributes may be particularly helpful in protected area assessments to better represent the regional heterogeneity in geographic priority settings. Gap analyses aim to determine how well the entire range of species, ecosystems, or environmental conditions is protected by a reserve network. Despite such a clear goal, identifying quantitative, general descriptors of representativeness and singularity (the commonness or uniqueness of the ecosystems of a protected area in the regional context) imposes a major challenge to reserve implementation (Overton and Leathwick 2001). Such descriptors should be based on ecosystem properties that can not only be identified in a particular site (e.g. National Parks or private reserves) but also be compared in the regional context under a common protocol (Austin and Margules 1986; Mackey et al. 1989). To our 
knowledge, only one study has incorporated remote sensing indicators of ecosystem functioning to analyze the singularity and representativeness of protected areas. Cabello et al. (2008) used the annual NDVI integral and relative range as surrogates of spatial patterns in ecosystem carbon gains to evaluate the Spanish Network of National Parks and to guide the implementation of the Uruguayan System of Protected Areas (Fig. 2). The functional space defined by these two variables characterizes the regional heterogeneity of ecosystem functioning in terms of productivity and seasonality (for details see AlcarazSegura 2008; Alcaraz-Segura et al. 2009a). National Parks in Spain and candidate sites in Uruguay were compared in this space with the rest of the natural ecosystems in each country. Those parks or sites exhibiting combinations of productivity and seasonality that were widespread in the regional context were considered representative, whereas sites corresponding to unique or rare combinations of productivity and seasonality were considered singular. The Spanish Network showed that traditional protection criteria were able to comprise the whole range of functional combinations, but were partially biased towards singular sites. In Uruguay, results demonstrated low functional heterogeneity of the extensive but homogeneous natural grasslands that dominate the country and revealed new reserve candidates to protect both representative and singular ecosystems. In both cases, the functional characterization of ecosystems allowed for the regional contextualization of protected areas based on ecological processes. This approach can help in developing layers in gap analyses for designing networks of protected areas in relation to ecosystem functioning, in addition to biodiversity features (e.g. biomes, ecosystems, habitats, species).

\section{Direct evaluation of ecosystem services}

Quantification of the supply of ecosystem services and subsequent dissemination of information to decision makers and the general public are critical for the sustainable management of natural resources and to support conservation decisions and landscape planning (Meyerson et al. 2005). However, in order to move forward, some limitations still need to be addressed. First, evaluations of ecosystem services from plot-based and static indicators do not provide complete coverage of a territory, and do not capture the rates of service supply and demand (Carpenter and Folke 2006). Second, there is an urgent need for quantifying changes in ecosystem dynamics, as well as their implications for ecosystem service provision (Boyd and Banzhaf 2007; Egoh et al. 2007). Finally, the areas that supply ecosystem services must be mapped to quantify the conservation benefits that they provide (Naidoo et al. 2008).

The combination of satellite-derived attributes with environmental databases and field data can be effectively used to estimate and monitor both the level of provision of ecosystem services over large areas (e.g. He et al. 2005; Nosetto et al. 2005) and their value with regard to the conservation interest of protected areas (Haslett et al. 2010). For example, He et al. (2005) presented a model for valuing ecosystem service in China based on satellite-derived estimates of NPP. Volante et al. (2012) and Caride et al. (2012), using remotely sensed data and modelling techniques, provided estimates of carbon-related services for forests and grasslands of South America. In addition, regional quantification of carbon gains in protected areas supports their protection given that they help address ecological problems related to climate change issues (Dudley et al. 2010).

Other services can also be estimated through satellite-derived descriptors, such as warming mitigation through evaporative cooling in tropical forests, or the effect of albedo on climate regulation through changes in the duration of snow-pack in boreal forests (Bonan 2008). Remote sensing data demonstrated that grassland afforestation in the 


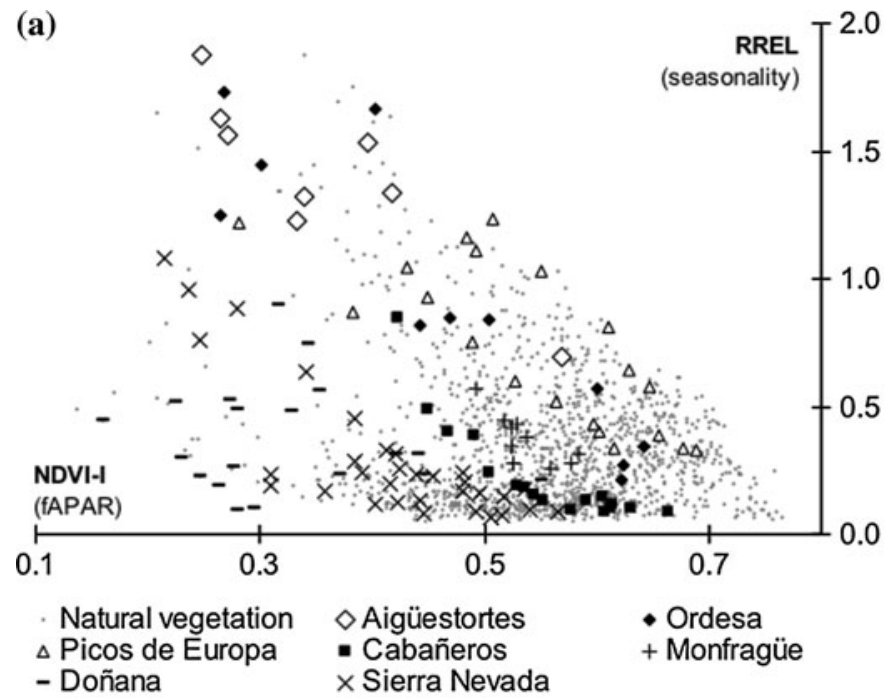

(b) $\times$ Sierra Nevada

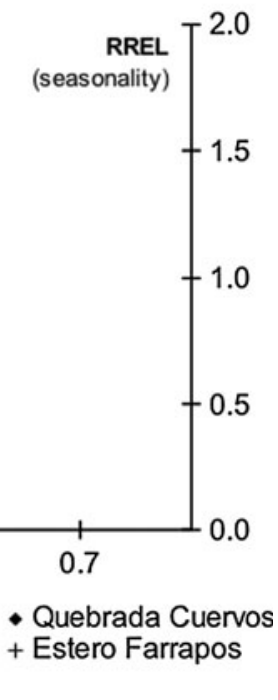

Fig. 2 Analysis of representativeness of Spanish national parks (a) and Uruguayan candidate protected areas (b) based on ecosystem functional attributes derived from remote sensing. For each country, the approach locates the protected areas in the functional space defined by the whole range of annual NDVI integrals (NDVI-I, an estimator of annual C gains) and the relative range of variation in light interception during the year (RREL, an indicator of seasonality). Points correspond to the discrete area defined by a pixel. Grey points correspond to natural (non-agricultural) areas. Protected sites coincident with repetitive combinations of productivity and seasonality were considered representative, while sites corresponding to unique or rare combinations were considered singular. (Adapted from Cabello et al. 2008)

Uruguay River basin increased evapotranspiration by $80 \%$, inducing a decrease in aquifer recharge and water supply (Nosetto et al. 2005). In addition, forage monitoring programs (e.g. Grigera et al. 2007) may also improve the estimation of services with market value, such as livestock production and game animals. In all cases, satellite-based functional 
attributes can be directly linked to ecosystem services, can be mapped, and allow for a direct incorporation of ecosystem service information into conservation planning.

Planning and monitoring ecological restorations

Ecological restoration is an important component of conservation policies aimed to re-establish the functioning of degraded ecosystems. The importance of planning restoration by defining objectives at the ecosystem level, specifically focusing on water, energy, and matter fluxes, is well recognized (Ehrenfeld 2000). Remote sensing techniques minimize the economic and logistic restrictions of monitoring programs (Korb and Fule 2008; Malmstrom et al. 2009), which are the most common restrictions for devising reliable monitoring systems in restoration plans (Ruiz-Jaén and Mitchell Aide 2005). Biophysical variables such as NPP, evapotranspiration, and albedo help define quantifiable objectives and actions that include ecosystem process dynamics. For example, biomass accumulation rate has been used as an indicator of nutrient dynamics restoration in tropical secondary forests (Feldpausch et al. 2004), while nutrient status has been evaluated from satellite images to assess the restoration potential of eucalypt grassy woodlands in Australia (Zerger et al. 2011). Tuxen et al. (2008) implemented a technique using NDVI to document vegetation colonization in a restored salt marsh, while Leon et al. (2012) used NDVI timeseries to evaluate vegetation responses to wildfires in different pre-fire restoration regimens. Evapotranspiration estimates derived from MODIS EVI and ground data (Nagler et al. 2005) have been used to evaluate water use by invasive Tamarix stands compared to native riparian species in the western United States (Nagler et al. 2008). This evaluation revealed a cost-effective restoration strategy, which eliminated the need for the complete removal and replacement of Tamarix.

Lastly, indicators of ecosystem functioning may also represent a valuable tool in proactive restoration initiatives, such as proposals to increase carbon sequestration (Harris et al. 2006), assess wetland restoration (Melesse et al. 2006), or characterize trends, memory effects, and resilience in large scale efforts (Walters 1986).

\section{Conclusions and perspectives}

The examples outlined in this article represent a sample of the applications of ecosystem functional descriptions in conservation biology (Fig. 1). The potential for using these ecosystem functioning attributes derives, on one hand, from the strong conceptual relationship between these attributes and the two central objectives of conservation practice, biodiversity preservation and conservation of ecosystem processes, and, on the other hand, from the possibility of using remotely sensed data to monitor them. The implementation of conservation actions, as well as the evaluation of the results of management interventions, requires information on functional aspects of different levels of organization (populations, species, communities, and ecosystems). As we have demonstrated, satellite-derived functional ecosystem variables can be used to better understand the abundance, distribution, and population dynamics of species of conservation concern, to assess the role of protected areas in environmental conservation and monitoring of environmental changes, to directly estimate the level of ecosystem services supply, and to design and monitor ecological restorations. In addition, remote sensing products not only provide accurate estimates of key functional variables, but also fulfill the key requirements of monitoring systems. 
The incorporation of new variables with a clear relationship to the functioning dynamics of ecosystems improves the possibility of diagnosing an "ill-functioning" ecosystem. Nonetheless, no matter how sophisticated the diagnostic tool, it cannot replace an in-depth analysis of the system, its natural history, and its environmental, socio-economic, geopolitical, and cultural context. Therefore, the approaches that we present in this study are not intended to replace current conservation practices, but rather to complement them. However, as in the field of medicine, a new analytical tool may help improve the diagnosis by identifying problems previously hidden, and as a result allow for better-informed decisions.

Acknowledgments We thank José María Iriondo and Francisco Lloret for their helpful comments. This paper is the result of two symposiums supported by the Ministerio de Asuntos Exteriores (AECID) (Project "Red temática para la evaluación del impacto de los cambios globales (vs locales) en el funcionamiento ecosistémico"). Financial support was also provided by FEDER funds, Junta de Andalucía (projects RNM6685 and SEGALERT P09-RNM-5048), Organismo Autónomo de Parques Nacionales (project 066/2007), Ministerio de Ciencia e Innovación (Proyecto CGL2010-22314) and Fundación MAPFRE (2008 call for projects).

\section{References}

Alcaraz-Segura D (2008) Remote sensing of ecosystem functioning in the Iberian Peninsula. Groundworks for biodiversity conservation in the face of global change effects. Universidad de Almería

Alcaraz-Segura D, Paruelo JM, Cabello J (2006) Identification of current ecosystem functional types in the Iberian Peninsula. Glob Ecol Biogeogr 15:200-212

Alcaraz-Segura D, Baldi G, Durante P, Garbulsky MF (2008a) Análisis de la dinámica temporal del NDVI en áreas protegidas: tres casos de estudio a distintas escalas espaciales, temporales y de gestión. Ecosistemas 17:108-117

Alcaraz-Segura D, Cabello J, Paruelo JM, Delibes M (2008b) Trends in the surface vegetation dynamics of the National Parks of Spain as observed by satellite sensors. Appl Veg Sci 11:431-440

Alcaraz-Segura D, Cabello J, Paruelo J (2009a) Baseline characterization of major Iberian vegetation types based on the NDVI dynamics. Plant Ecol 202:13-29

Alcaraz-Segura D, Cabello J, Paruelo JM, Delibes M (2009b) Use of descriptors of ecosystem functioning for monitoring a national park network: a remote sensing approach. Environ Manage 43:38-48

Allen TFH, Hoekstra TW (1992) Toward a unified ecology. Columbia University Press, New York, pp 384

Armsworth PR, Chan KMA, Daily GC, Ehrlich PR, Kremen C, Ricketts TH, Sanjayan MA (2007) Ecosystem-service science and the way forward for conservation. Conserv Biol 21:1383-1384

Austin MP, Margules CR (1986) Assessing representativeness. In: Usher MB (ed) Wildlife conservation evaluation. Chapman and Hall, London, pp 45-67

Bala G, Caldeira K, Wickett M, Phillips TJ, Lobell DB, Delire C, Mirin A (2007) Combined climate and carbon-cycle effects of large-scale deforestation. Proc Natl Acad Sci USA 104:6550-6555

Bardsen BJ, Tveraa T (2012) Density-dependence vs. density-independence-linking reproductive allocation to population abundance and vegetation greenness. J Anim Ecol 81:364-376

Bonan GB (2008) Forests and climate change: forcings, feedbacks, and the climate benefits of forests. Science 320:1444-1449

Boone RB, Thirgood SJ, Hopcraft JGC (2006) Serengeti wildebeest migratory patterns modeled from rainfall and new vegetation growth. Ecology 87:1987-1994

Boyce MS (1992) Population viability analysis. Annu Rev Ecol Syst 23:481-506

Boyd J, Banzhaf S (2007) What are ecosystem services? The need for standardized environmental accounting units. Ecol Econ 63:616-626

Cabello J, Alcaraz-Segura D, Altesor A, Delibes M, Liras E (2008) Funcionamiento ecosistémico y evaluación de prioridades geográficas en conservación. Ecosistemas 17:53-63

Callaghan TV, Björn LO, Chernov Y, Chapin T, Christensen TR, Huntley B, Ims RA, Johansson M, Jolly D, Jonasson S, Matveyeva N, Panikov N, Oechel W, Shaver G (2004) Effects on the function of arctic ecosystems in the short- and long-term perspectives. Ambio 33:448-458

Callicott JB, Crowder LB, Mumford K (1999) Current normative concepts in conservation. Conserv Biol $13: 22-35$ 
Caride C, Piñeiro G, Paruelo JM (2012) How does agricultural management modify ecosystem services in the argentine Pampas? The effects on soil C dynamics. Agric Ecosyst Environ 154:23-33

Carpenter SR, Folke C (2006) Ecology for transformation. Trends Ecol Evol 21:309-315

Cleland EE, Chuine I, Menzel A, Mooney HA, Schwartz MD (2007) Shifting plant phenology in response to global change. Trends Ecol Evol 22:357-365

Coops NC, Wulder MA, Iwanicka D (2009) Demonstration of a satellite-based index to monitor habitat at continental-scales. Ecol Ind 9:948-958

Crabtree R, Potter C, Mullen R, Sheldon J, Huang S, Harmsen J, Rodman A, Jean C (2009) A modeling and spatio-temporal analysis framework for monitoring environmental change using NPP as an ecosystem indicator. Remote Sens Environ 113:1486-1496

Dale VH, Beyeler SC (2001) Challenges in the development and use of ecological indicators. Ecol Ind $1: 3-10$

Dudley N, Stolton S, Belokurov A, Krueger L, Lopoukhine N, MacKinnon K, Sandwith T, Sekhran N (2010) Natural Solutions: Protected areas helping people cope with climate change. IUCNWCPA, TNC, UNDP, WCS, The World Bank and WWF, Gland, Switzerland, Washington DC and New York, USA, p 130

Durante P, Oyonarte C, Valladares F (2009) Influence of land-use types and climatic variables on seasonal patterns of NDVI in Mediterranean Iberian ecosystems. Appl Veg Sci 12:177-185

Duro DC, Coops NC, Wulder MA, Han T (2007) Development of a large area biodiversity monitoring system driven by remote sensing. Prog Phys Geogr 31:235-260

Egoh B, Rouget M, Reyers B, Knight AT, Cowling RM, van Jaarsveld AS, Welz A (2007) Integrating ecosystem services into conservation assessments: a review. Ecol Econ 63:714-721

Ehrenfeld JG (2000) Defining the limits of restoration: the need for realistic goals. Restor Ecol 8:2-9

Fang JY, Piao SL, Zhou LM, He JS, Wei FY, Myneni RB, Tucker CJ, Tan K (2005) Precipitation patterns alter growth of temperate vegetation. Geophys Res Lett 32. doi:10.1029/2005GL024231

Feldpausch TR, Rondon MA, Fernandes ECM, Riha SJ, Wandelli E (2004) Carbon and nutrient accumulation in secondary forests regenerating on pastures in central Amazonia. Ecol Appl 14:164-176

Fernández N, Paruelo JM, Delibes M (2010) Ecosystem functioning of protected and altered Mediterranean environments: a remote sensing classification in Doñana, Spain. Remote Sens Environ 114:211-220

Fischer DT, Still CJ, Williams AP (2009) Significance of summer fog and overcast for drought stress and ecological functioning of coastal California endemic plant species. J Biogeogr 36:783-799

Franklin J (2010) Moving beyond static species distribution models in support of conservation biogeography. Divers Distrib 16:321-330

Frid CLJ, Paramor OAL, Brockington S, Bremner J (2008) Incorporating ecological functioning into the designation and management of marine protected areas. Hydrobiologia 606:69-79

Garbulsky MF, Paruelo JM (2004) Remote sensing of protected areas to derive baseline vegetation functioning characteristics. J Veg Sci 15:711-720

García M, Oyonarte C, Villagarcía L, Contreras S, Domingo F, Puigdefabregas J (2008) Monitoring land degradation risk using ASTER data: the non-evaporative fraction as an indicator of ecosystem function. Remote Sens Environ 112:3720-3736

Gillespie TW, Foody GM, Rocchini D, Giorgi AP, Saatchi S (2008) Measuring and modelling biodiversity from space. Prog Phys Geogr 32:203-221

Goldman RL, Tallis H, Kareiva P, Daily GC (2008) Field evidence that ecosystem service projects support biodiversity and diversify options. Proc Natl Acad Sci USA 105:9445-9448

Gower ST, Kucharik CJ, Norman JM (1999) Direct and indirect estimation of leaf area index, f(APAR), and net primary production of terrestrial ecosystems. Remote Sens Environ 70:29-51

Grande JM, Serrano D, Tavecchia G, Carrete M, Ceballos O, Diaz-Delgado R, Tella JL, Donazar JA (2009) Survival in a long-lived territorial migrant: effects of life-history traits and ecological conditions in wintering and breeding areas. Oikos 118:580-590

Grigera G, Oesterheld M, Pacin F (2007) Monitoring forage production for farmers' decision making. Agric Syst 94:637-648

Guisan A, Thuiller W (2005) Predicting species distribution: offering more than simple habitat models. Ecol Lett 8:993-1009

Hall FG, Huemmrich KF, Goetz SJ, Sellers PJ, Nickeson JE (1992) Satellite remote sensing of surface energy balance: success, failures, and unresolved issues in FIFE. J Geophys Res Atmos 97:19061-19089

Harris JA, Hobbs RJ, Higgs E, Aronson J (2006) Ecological restoration and global climate change. Restor Ecol 14:170-176

Hartley AJ, Nelson A, Mayaux P, Grégoire J-M (2007) The assessment of african protected areas. Luxembourg, p 77 
Haslett JR, Berry PM, Bela G, Jongman RHG, Pataki G, Samways MJ, Zobel M (2010) Changing conservation strategies in Europe: a framework integrating ecosystem services and dynamics. Biodivers Conserv 19(10):2963-2977

Havstad KM, Herrick JE (2003) Long-term ecological monitoring. Arid Land Res Manag 17:389-400

He H, Yang M, Pan Y, Zhu W (2005) Measurement of terrestrial ecosystem service value in China based on remote sensing. In: International Geoscience and Remote Sensing Symposium (IGARSS), pp 2965-2968

Hooper DU, Chapin FS, Ewel JJ, Hector A, Inchausti P, Lavorel S, Lawton JH, Lodge DM, Loreau M, Naeem S, Schmid B, Setala H, Symstad AJ, Vandermeer J, Wardle DA (2005) Effects of biodiversity on ecosystem functioning: a consensus of current knowledge. Ecol Monogr 75:3-35

Horning N, Robinson JA, Sterling EJ, Turner W, Spector S (2010) Remote sensing for ecology and conservation. Oxford University Press, New York

Huete A, Didan K, Miura T, Rodriguez EP, Gao X, Ferreira LG (2002) Overview of the radiometric and biophysical performance of the MODIS vegetation indices. Remote Sens Environ 83:195-213

Hurlbert AH, Haskell JP (2003) The effect of energy and seasonality on avian species richness and community composition. Am Nat 161:83-97

Ito TY, Miura N, Lhagvasuren B, Enkhbileg D, Takatsuki S, Tsunekawa A, Jiang ZW (2005) Preliminary evidence of a barrier effect of a railroad on the migration of Mongolian gazelles. Conserv Biol 19:945-948

Jax K (2010) Ecosystem functioning. Cambridge University Press, Cambridge

Jenkins R, Bedford WB (1973) The use of natural areas to establish environmental baselines. Biol Conserv 5:168-174

Jobbagy EG, Sala OE, Paruelo JM (2002) Patterns and controls of primary production in the Patagonian steppe: a remote sensing approach. Ecology 83:307-319

Julien Y, Sobrino JA (2009) The yearly land cover dynamics (YLCD) method: an analysis of global vegetation from NDVI and LST parameters. Remote Sens Environ 113:329-334

Kerr JT, Ostrovsky M (2003) From space to species: ecological applications for remote sensing. Trends Ecol Evol 18(6):299-305

Knapp AK, Smith MD (2001) Variation among biomes in temporal dynamics of aboveground primary production. Science 291:481-484

Korb JE, Fule PZ (2008) Intra- and interannual vegetation change: implications for long-term research. Restor Ecol 16:5-11

Kustas W, Anderson M (2009) Advances in thermal infrared remote sensing for land surface modeling. Agric For Meteorol 149:2071-2081

Leon JRR, van Leeuwen WJD, Casady GM (2012) Using MODIS-NDVI for the modeling of post-wildfire vegetation response as a function of environmental conditions and pre-fire restoration treatments. Remote Sens 4:598-621

Liang S (2000) Narrowband to broadband conversions of land surface albedo. I Algorithms. Remote Sens Environ 76:213-238

Lindenmayer D, Hunter M (2010) Some guiding concepts for conservation biology. Conserv Biol 24:1459-1468

Lyons EA, Jin Y, Randerson JT (2008) Changes in surface albedo after fire in boreal forest ecosystems of interior Alaska assessed using MODIS satellite observations. J Geophys Res G Biogeosci 113:G02012. doi:10.1029/2007JG000606

Mackey BG, Nix HA, Stein JA, Cork SE, Bullen FT (1989) Assessing the representativeness of the wet tropics of Queensland world heritage property. Biol Conserv 50:279-303

Madhusudan MD (2004) Recovery of wild large herbivores following livestock decline in a tropical Indian wildlife reserve. J Appl Ecol 41(5):858-869

Malmstrom CM, Butterfield HS, Barber C, Dieter B, Harrison R, Qi J, Riaño D, Schrotenboer A, Stone S, Stoner CJ, Wirka J (2009) Using remote sensing to evaluate the influence of grassland restoration activities on ecosystem forage provisioning services. Restor Ecol 17:526-538

Manseau M, Huot J, Crete M (1996) Effects of summer grazing by caribou on composition and productivity of vegetation: community and landscape level. J Ecol 84:503-513

McNaughton SJ, Oesterheld M, Frank DA, Williams KJ (1989) Ecosystem-level patterns of primary productivity and herbivory in terrestrial habitats. Nature 341:142-144

Meine C, Soule M, Noss RF (2006) "A mission-driven discipline": the growth of conservation biology. Conserv Biol 20:631-651

Melesse AM, Oberg J, Nangia V, Beeri O, Baumgartner D (2006) Spatiotemporal dynamics of evapotranspiration at the Glacial Ridge prairie restoration in northwestern Minnesota. Hydrol Process 20:1451-1464 
Meyerson LA, Baron J, Melillo JM, Naiman RJ, O’Malley RI, Orians G, Palmer MA, Pfaff ASP, Running SW, Sala OE (2005) Aggregate measures of ecosystem services: can we take the pulse of nature? Front Ecol Environ 3:56-59

Mildrexler DJ, Zhao MS, Running SW (2009) Testing a MODIS Global Disturbance Index across North America. Remote Sens Environ 113:2103-2117

Monteith JL (1977) Climate and the efficiency of crop production in Britain. Philos Trans R Soc Lond B 281:277-294

Moran MS, Jackson RD (1991) Assessing the spatial distribution of evapotranspiration using remotely sensed inputs. J Environ Qual 20:725-737

Mueller T, Olson KA, Dressler G, Leimgruber P, Fuller TK, Nicolson C, Novaro AJ, Bolgeri MJ, Wattles D, DeStefano S, Calabrese JM, Fagan WF (2011) How landscape dynamics link individual- to populationlevel movement patterns: a multispecies comparison of ungulate relocation data. Glob Ecol Biogeogr 20:683-694

Musiega DE, Kazadi S-N (2004) Simulating the East African wildebeest migration patterns using GIS and remote sensing. Afr J Ecol 42:355-362

Naeem S (2002) Ecosystem consequences of biodiversity loss: the evolution of a paradigm. Ecology 83:1537-1552

Nagler PL, Scott RL, Westenburg C, Cleverly JR, Glenn EP, Huete AR (2005) Evapotranspiration on western U.S. rivers estimated using the Enhanced Vegetation Index from MODIS and data from eddy covariance and Bowen ratio flux towers. Remote Sens Environ 97:337-351

Nagler PL, Glenn EP, Didan K, Osterberg J, Jordan F, Cunningham J (2008) Wide-area estimates of stand structure and water use of Tamarix spp. on the Lower Colorado River: implications for restoration and water management projects. Restor Ecol 16:136-145

Naidoo R, Balmford A, Costanza R, Fisher B, Green RE, Lehner B, Malcolm TR, Ricketts TH (2008) Global mapping of ecosystem services and conservation priorities. Proc Natl Acad Sci USA 105:9495-9500

Nemani R, Hashimoto H, Votava P, Melton F, Wang W, Michaelis A, Mutch L, Milesi C, Hiatt S, White M (2009) Monitoring and forecasting ecosystem dynamics using the Terrestrial Observation and Prediction System (TOPS). Remote Sens Environ 113:1497-1509

Nosetto MD, Jobbagy EG, Paruelo JM (2005) Land-use change and water losses: the case of grassland afforestation across a soil textural gradient in central Argentina. Glob Change Biol 11:1101-1117

Oesterheld M, Sala OE, McNaughton SJ (1992) Effect of animal husbandry on herbivore-carrying capacity at a regional scale. Nature 356:234-236

Oesterheld M, DiBella CM, Kerdiles H (1998) Relation between NOAA-AVHRR satellite data and stocking rate in grasslands. Ecol Appl 8:207-212

Ollinger SV, Richardson AD, Martin ME, Hollinger DY, Frolking SE, Reich PB, Plourde LC, Katul GG, Munger JW, Oren R, Smith M-L, Paw UKT, Bolstad PV, Cook BD, Day MC, Martin TA, Monson RK, Schmid HP (2008) Canopy nitrogen, carbon assimilation, and albedo in temperate and boreal forests: functional relations and potential climate feedbacks. Proc Natl Acad Sci USA 105:19336-19341

Otterman J, Karnieli A, Brakke T, Koslowsky D, Bolle H-J, Starr D, Schmidt H (2002) Desert scrub optical density and spectral-albedo ratios of impacted-to-protected areas by model inversion. Int $\mathrm{J}$ Remote Sens 23:3959-3970

Overton JM, Leathwick JR (2001) Measuring ecological distinctiveness. Department of Conservation, Wellington, New Zealand

Oyonarte C, Alcaraz-Segura D, Oyarzabal M, Paruelo JM, Cabello J (2010) Sistema de apoyo a la gestión de reservas de la biosfera basado en el monitoreo de la productividad primaria: ensayo en Cabo de GataNíjar (Almería-España). In: Araya P, Clüsener-Godt M (eds) Reservas de la Biosfera: Su contribución a la provisión de servicios de los ecosistemas. Experiencias exitosas en Iberoamérica, UNESCO, Paris, pp 119-140

Paruelo JM, Lauenroth WK, Burke IC, Sala OE (1999) Grassland precipitation-use efficiency varies across a resource gradient. Ecosystems 2:64-68

Paruelo JM, Jobbagy EG, Sala OE (2001) Current distribution of ecosystem functional types in temperate South America. Ecosystems 4:683-698

Paruelo JM, Piñeiro G, Oyonarte C, Alcaraz-Segura D, Cabello J, Escribano P (2005) Temporal and spatial patterns of ecosystem functioning in protected and areas in southeastern Spain. Appl Veg Sci 8:93-102

Paruelo JM, Putz S, Weber G, Bertiller M, Golluscio RA, Aguiar MR, Wiegand T (2008) Long-term dynamics of a semiarid grass steppe under stochastic climate and different grazing regimes: a simulation analysis. J Arid Environ 72:2211-2231

Pelkey NW, Stoner CJ, Caro TM (2000) Vegetation in Tanzania: assessing long term trends and effects of protection using satellite imagery. Biol Conserv 94:297-309 
Pereira HM, David Cooper H (2006) Towards the global monitoring of biodiversity change. Trends Ecol Evol 21:123-129

Pettorelli N, Vik JO, Mysterud A, Gaillard JM, Tucker CJ, Stenseth NC (2005) Using the satellite-derived NDVI to assess ecological responses to environmental change. Trends Ecol Evol 20:503-510

Pettorelli N, Pelletier F, von Hardenberg A, Festa-Bianchet M, Cote SD (2007) Early onset of vegetation growth vs. rapid green-up: impacts on juvenile mountain ungulates. Ecology 88:381-390

Pettorelli N, Ryan S, Mueller T, Bunnefeld N, Jedrzejewska B, Lima M, Kausrud K (2011) The Normalized Difference Vegetation Index (NDVI): unforeseen successes in animal ecology. Clim Res 46:15-27

Pfeifer M, Disney M, Quaife T, Marchant R (2012) Terrestrial ecosystems from space: a review of earth observation products for macroecology applications. Glob Ecol Biogeogr 21:603-624

Phillips LB, Hansen AJ, Flather CH (2008) Evaluating the species energy relationship with the newest measures of ecosystem energy: NDVI versus MODIS primary production (vol 112, p 3538, 2008). Remote Sens Environ 112:4380

Phillips LB, Hansen AJ, Flather CH, Robison-Cox J (2010) Applying species-energy theory to conservation: a case study for North American birds. Ecol Appl 20:2007-2023

Piñeiro G, Oesterheld M, Paruelo JM (2006) Seasonal variation in aboveground production and radiationuse efficiency of temperate rangelands estimated through remote sensing. Ecosystems 9:357-373

Potter CS, Brooks V (1998) Global analysis of empirical relations between annual climate and seasonality of NDVI. Int J Remote Sens 19:2921-2948

Rasmussen HB, Wittemyer G, Douglas-Hamilton I (2006) Predicting time-specific changes in demographic processes using remote-sensing data. J Appl Ecol 43:366-376

Reed BC, Brown JF, Vanderzee D, Loveland TR, Merchant JW, Ohlen DO (1994) Measuring phenological variability from satellite imagery. J Veg Sci 5:703-714

Rodriguez C, Bustamante J (2003) The effect of weather on lesser kestrel breeding success: can climate change explain historical population declines? J Anim Ecol 72:793-810

Rouget M, Cowling RM, Pressey RL, Richardson DM (2003) Identifying spatial components of ecological and evolutionary processes for regional conservation planning in the Cape Floristic Region, South Africa. Divers Distrib 9:191-210

Ruimy A, Saugier B, Dedieu G (1994) Methodology for the estimation of terrestrial net primary production from remotely sensed data. J Geophys Res 99:5263-5283

Ruiz-Jaén MC, Mitchell Aide T (2005) Vegetation structure, species diversity, and ecosystem processes as measures of restoration success. For Ecol Manage 218:159-173

Running SW, Nemani RR, Heinsch FA, Zhao M, Reeves M, Hashimoto H (2004) A continuous satellitederived measure of global terrestrial primary production. Bioscience 54:547-560

Schaub M, Kania W, Koppen U (2005) Variation of primary production during winter induces synchrony in survival rates in migratory white storks Ciconia ciconia. J Anim Ecol 74:656-666

Schonewald-Cox C (1988) Boundaries in the protection of nature reserves. Bioscience 38:480-486

Soulé ME, Wilcox B (1980) Conservation biology: an evolutionary-ecological perspective. Sinauer Associates Inc, Sunderland

Tang Z, Fang J, Sun J, Gaston KJ (2011) Effectiveness of protected areas in maintaining plant production. PLoS ONE 6(4):e19116

Tuanmu MN, Vina A, Roloff GJ, Liu W, Ouyang ZY, Zhang HM, Liu JG (2011) Temporal transferability of wildlife habitat models: implications for habitat monitoring. J Biogeogr 38:1510-1523

Tucker CJ (1979) Red and photographic infrared linear combinations for monitoring vegetation. Remote Sens Environ 8:127-150

Turner DP, Ritts WD, Cohen WB, Gower ST, Running SW, Zhao M, Costa MH, Kirschbaum AA, Ham JM, Saleska SR, Ahl DE (2006) Evaluation of MODIS NPP and GPP products across multiple biomes. Remote Sens Environ 102:282-292

Tuxen KA, Schile LM, Kelly M, Siegel SW (2008) Vegetation colonization in a restoring tidal marsh: a remote sensing approach. Restor Ecol 16:313-323

Verboom J, Schippers P, Cormont A, Sterk M, Vos CC, Opdam PFM (2010) Population dynamics under increasing environmental variability: implications of climate change for ecological network design criteria. Landsc Ecol 25:1289-1298

Virginia RA, Wall DH, Levin SA (2001) Principles of ecosystem function. Encyclopedia of biodiversity. Academic Press, San Diego, pp 345-352

Volante JN, Alcaraz-Segura D, Mosciaro MJ, Viglizzo EF, Paruelo JM (2012) Ecosystem functional changes associated with land clearing in NW Argentina. Agric Ecosyst Environ 154:12-22

Walters CJ (1986) Adaptive management of natural resources. McGraw-Hill, New York

Wiegand T, Naves J, Garbulsky MF, Fernandez N (2008) Animal habitat quality and ecosystem functioning: exploring seasonal patterns using NDVI. Ecol Monogr 78:87-103 
Wittemyer G (2011) Effects of economic downturns on mortality of wild African Elephants. Conserv Biol 25:1002-1009

Wittemyer G, Rasmussen HB, Douglas-Hamilton I (2007) Breeding phenology in relation to NDVI variability in free-ranging African elephant. Ecography 30:42-50

Zerger A, McIntyre S, Gobbett D, Stol J (2011) Remote detection of grassland nutrient status for assessing ground layer vegetation condition and restoration potential of eucalypt grassy woodlands. Landsc Urban Plan 102:226-233 